\title{
Recovery Effect of Flavonoids from Morus alba Fruits on Alloxan-induced Pancreatic Islet in Zebrafish (Dinio rerio)
}

\author{
Kyeong-Hwa Seo • Youn-Hee Nam • Young-Eon Kim • Eock-Kee Hong • \\ Bin-Na Hong · Tong-Ho Kang • Nam-In Baek*
}

\section{오디 Flavonoid의 alloxan 처리 zebrafish 췌장섬에 대한 회복효과}

\author{
서경화 · 남윤희 · 김영언 · 홍억기 · 홍빛나·강동호 · 백남인*
}

Received: 15 September 2014 / Accepted: 19 November 2014 / Published Online: 31 March 2015

(C) The Korean Society for Applied Biological Chemistry 2015

\begin{abstract}
Abastract Flavonoids from Morus alba fruits were evaluated for recovery effect on the damage of alloxan-induced pancreatic islet in zebrafish. Alloxan treatment on the zebrafish embryo surely decreased the pancreatic islet size $(p<0.001)$. Rutin, isoquercetin, and quercetin very significantly recovered the size $(p<0.001)$ and the fluorescence intensity of pancreatic islet.
\end{abstract}

Keywords alloxan ' anti-diabetics flavonoid $\cdot$ Morus alba . pancreatic islet $\cdot$ zebrafish

K.-H. Seo $\cdot$ Y.-H. Nam $\cdot$ T.-H. Kang $\cdot$ N.-I. Baek

Graduate School of Biotechnology and Department of Oriental Medicinal Biotechnology, Kyung Hee University, Yongin 446-701, Republic of Korea

Y.-E. Kim

Korea Food Research Institute, Sungnam 463-746, Republic of Korea

E.-K. Hong

School of Biotechnology and Bioengineering, Kangwon National University, Chunchon 200-701, Republic of Korea

\section{B.-N. Hong}

Department of Audiology, Nambu University, Gwangju 506-706, Republic of Korea

*Corresponding author (N.-I. Baek: nibaek@khu.ac.kr)

This is an Open Access article distributed under the terms of the Creative Commons Attribution Non-Commercial License (http://creativecommons. org/licenses/by-nc/3.0/) which permits unrestricted non-commercial use, distribution, and reproduction in any medium, provided the original work is properly cited.
현재 인슐린 의존성 당뇨병(제 1 형 당뇨병)의 연구 시, 실험동물 에 당뇨를 유발시키기 위해서는 주로 alloxan 과 streptozotocin이 이용되고 있다(Lee, 2009). Alloxan은 선택적으로 췌장의 베타 세포에 빠르게 축적되어, 베타세포의 glucokinase를 억제하여 인 슐린 분비를 감소시킨다(Lenzen, 2008). Zebrafish (Danio rerio)는 인도 원산 잉어과의 소형 열대 담수어이다. 체외 수정 을 하고 embryo가 투명하여 형광 염색을 하여 췌장섬을 포함 하여 각종 장기를 구성하는 특정세포들의 형성 및 분화 과정을 일반 해부현미경 하에서 쉽게 관찰 할 수 있다(Kim과 $\mathrm{Kim}$, 2003). 따라서 본 연구에서는 zebrafish의 embryo에 alloxan을 처리하여 체내 췌장섬의 손상을 확인하여 당뇨 유발을 평가하 고자 하였으며, 손상된 췌장섬에 뽕나무과실에서 분리한 플라보 노이드를 투여하여 손상된 췌장섬의 회복효과를 평가하고자 하 였다. 췌장섬의 손상 정도는 2-NBDG (2-(N-7-nitrobenz-2-oxa1,3-diazol-4-yl)amino)-2-deoxyglucose로 염색하여 확인하였다. 2-NBDG는 췌장섬의 형태학적 관찰을 가능하게 한다. 이를 이 용하면 glucose의 축적이나 대사 메커니즘을 관찰 할 수 있다 (Zou, 2005). 또한 2-NBDG는 살아있는 세포에만 흡수 가능 하 기 때문에, 본 연구에서는 fluorescence intensity 측정을 통하여 췌장섬의 변화를 관찰 하였다.

뽕나무(Morus alba)는 뽕나무과(Moraceae)에 속하는 낙엽교 목으로 우리나라 전역에 분포하고 있다. 열매는 장과로 6 월에 흑색으로 익는다(Jung, 2002). 뽕나무 열매인 오디는 상심자(桑 子), 상실(桑實) 흑심(黑愖) 등으로 불리며 백발을 검게 하며, 소 갈을 덜어주고 오장을 이롭게 하는 자양 강장제로 널리 사용되 고 있다(Kim, 1991; Park,1997). 오디 추출물로부터 퇴행성 관 절염 억제, 골다공증 치료 및 항염증에 대한 활성이 보고되어 있다(Park과 Jung, 2008; Lee, 2009; Seo, 2014). 또한 혈당상 승효소의 활성억제 연구(Chae, 2012), 제 1형 당뇨 연구(Kim, 2006), 제 2형 당뇨 연구(Hunyadi, 2012) 및 인슐린 의존형 당 뇨병 및 인슐린 비의존형 당뇨병 모델 동물을 이용하여 오디의 
항당뇨 효과에 대한 선행 연구가 진행된 바 있다(Gulubova와 Boiadzhiev, 1975; Kim, 1996). 하지만 오디에 대하여 zebrafish 를 이용한 항당뇨 효능에 대한 연구는 아직까지 보고 된 바가 없다.

오디 $(15.4 \mathrm{~kg})$ 에 $100 \% \mathrm{EtOH}(35 \mathrm{~L} \times 1)$ 및 $70 \% \mathrm{EtOH}(35 \mathrm{~L} \times 2)$ 을 가하여 실온에서 24 시간 추출한 후 여과지로 여과하였다. 얻 어진 여액을 감압 농축한 $\mathrm{EtOH}$ 추출물 $(2219 \mathrm{~g})$ 에 대하여 용매 의 극성에 따라 EtOAc, $n-\mathrm{BuOH}$ 및 물로 순차 분획하고 각 분획을 감압 농축하여 3 개의 분획, $\mathrm{MAE}(41 \mathrm{~g}), \mathrm{MAB}$ $(247 \mathrm{~g}), \mathrm{MAW}(1949 \mathrm{~g})$ 을 얻었다. EtOAc 분획 $(40 \mathrm{~g})$ 에 대하 여 $\mathrm{SiO}_{2}$ c.c. [ $\Phi 9.0 \times 14 \mathrm{~cm}, n$-hexane-EtOAc $=10: 1 \rightarrow 8: 1 \rightarrow 6: 1$ $\rightarrow 3: 1 \rightarrow 1: 1$ (각 $12 \mathrm{~L}$ 씩) $\mathrm{CHCl}_{3}-\mathrm{MeOH}=8: 1 \rightarrow 6: 1 \rightarrow 4: 1 \rightarrow 1: 1$ (각 $10 \mathrm{~L}$ 씩)]를 실시하여 14 개의 분획물(MAE-1-MAE-14)을 얻었다. MAE-13 $\left(800 \mathrm{mg}, \mathrm{Ve} / \mathrm{Vt}\right.$ 0.821-0.874)에 대하여 $\mathrm{SiO}_{2}$ c.c. $\left(\Phi \quad 9.0 \times 14 \mathrm{~cm}, \mathrm{CHCl}_{3}-\mathrm{MeOH}-\right.$ water $=16: 3: 1 \rightarrow 12: 3: 1$, 각 $3 \mathrm{~L}$ 씩)를 실시하여 30 개의 분획물(MAE-13-1-MAE-13-30)으로 나누었고, 화합물 1 [MAE-13-15, $24 \mathrm{mg}, \mathrm{Ve} / \mathrm{Vt}$ 0.186-0.202, TLC (RP-18 $\left.\left.\mathrm{F}_{254} \mathrm{~s}\right) \mathrm{R}_{\mathrm{f}} 0.68, \mathrm{MeOH}-w a t e r(3: 1)\right]$ 을 분리하였다. MAE-13-22 (42 mg, Ve/Vt 0.380-0.411)에 대하여 ODS c.c. $(\Phi 2 \times 5 \mathrm{~cm}, \mathrm{MeOH}-w a t e r=1: 1,0.3 \mathrm{~L}$ )를 실시하여 8 개의 분획물 (MAE-13-22-1-MAE-13-22-8)으로 나누었고, 화합물 2 [MAE13-22-5, $2.7 \mathrm{mg}$, Ve/Vt 0.486-0.502, TLC (RP-18 $\left.\mathrm{F}_{254} \mathrm{~S}\right) \mathrm{R}_{\mathrm{f}}$ $0.52, \mathrm{MeOH}-w a t e r(1: 1)]$ 를 분리하였다. $n$ - $\mathrm{BuOH}$ 분획 $(247 \mathrm{~g})$ 에 대하여 당을 제거하기 위해 Diaion HP-20 c.c. [ $\Phi 12 \times 38$ $\mathrm{cm}$, water $(8 \mathrm{~L}) \quad 50 \% \mathrm{MeOH}(4 \mathrm{~L}) \quad 100 \% \mathrm{MeOH}(8 \mathrm{~L})$ 를 실 시하여 8 개의 분획물(MAB-1-MAB-8)을 얻었다. 이 중에서 MAB-5 (1.31 g, Ve/Vt 0.522-0.601)에 대하여 ODS c.c. ( $\Phi$ $4.5 \times 10 \mathrm{~cm}, \mathrm{MeOH}-w a t e r=2: 3,1.4 \mathrm{~L}$ )를 실시하여 12 개의 분획 물(MAB-5-1-MAB-5-12)으로 나누었다. MAB-5-7 (271 mg, $\mathrm{Ve} / \mathrm{Vt}$ 0.247-0.369)에 대하여 $\mathrm{SiO}_{2}$ c.c. (Ф $2.5 \times 15 \mathrm{~cm}, \mathrm{CHCl}_{3}$ $\mathrm{MeOH}$-water $=8: 3: 1,3.6 \mathrm{~L})$ 를 실시하여 12 개의 분획물 $(\mathrm{MAB}-5-$ 7-1-MAB-5-7-12)으로 나누었고, 화합물 3 [MAB-5-7-6, 11.4 $\mathrm{mg}, \mathrm{Ve} / \mathrm{Vt}$ 0.104-0.185, TLC (RP-18 $\left.\mathrm{F}_{254} \mathrm{~S}\right) \mathrm{R}_{\mathrm{f}} 0.35$, MeOHwater (3:2)]와 화합물 4 [MAB-5-7-9, $58 \mathrm{mg}, \mathrm{Ve} / \mathrm{Vt} 0.210$ 0.275 , TLC (RP-18 $\left.\left.\mathrm{F}_{254} \mathrm{~S}\right) \mathrm{R}_{\mathrm{f}} 0.28, \mathrm{MeOH}-w a t e r(3: 2)\right]$ 를 분 리하였다. EtOAc와 $n$ - BuOH 분획에 대하여 silica gel 및 ODS column chromatography를 반복 수행하여 4종의 flavonoid를 분 리, 정제 하였으며, NMR, MS, IR 등의 spectroscopic data를 해석하여 qurcetin (1), astragalin (2), isoquercetin (3) 및 rutin (4)으로 각각 구조 동정하였다.

실험에 사용한 alloxan monohydrate 및 sea salt는 Sigma Chemical Co. (USA)로부터 구입하였다. 2-NBDG는 Invitrogen (USA) 제품을 사용하였다. 형광현미경은 Olympus 1 X70 (Olympus, Japan) 를 사용하였다. 이미지 분석을 위한 소프트웨 어는 Focus Lite (Focus Co, Korea)와 Image J (National Institutes of Health, USA)를 사용하였다.

알과 성어를 분리하기 위한 망을 설치한 수조에 암컷과 수컷 을 1:1 비율로 넣고 12시간 후에 zebrafish embryo를 수집하였 다. 채취 후에 $0.03 \%$ sea salt solution을 사용하여 3회 세척하 여 이물질 등을 제거하고 28.5 광주기(14 light/10 dark)가 설정 된 인큐베이터에서 사육하였다. Zebrafish 췌장섬의 크기 변화 를 통한 항당뇨 효능을 측정하기 위하여 $5 \mathrm{dpf}$ (day post fertilization)의 zebrafish larvae를 96 well에 위치시킨 후 25 $\mu \mathrm{M}$ 2-NBDG로 12시간 동안 염색하였다. 이후 $100 \mu \mathrm{M}$ alloxan

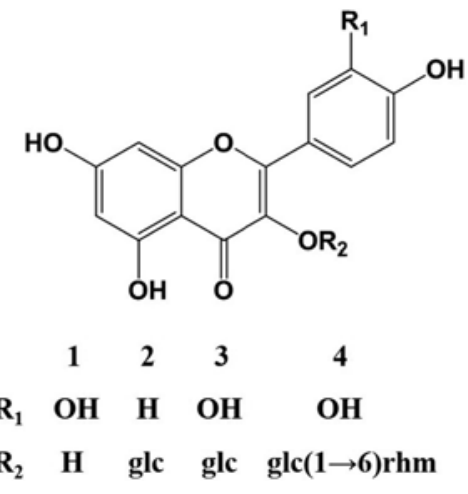

Fig. 1 Structure of compounds 1-4.

에 15 분간 노출시켰으며, $0.03 \%$ sea salt solution으로 바꾸어 5 시간동안 노출하였다. 직접적인 췌장섬의 관찰을 위해 형광현미 경을 사용하였으며, 관찰 전에 $25 \mu \mathrm{M} 2-\mathrm{NBDG}$ 로 1 시간 동안 다시 염색 하였다. 1차 현미경 촬영 후에 오디에서 분리한 4종 의 flavonoid 와 양성대조 약물인 glimepiride를 각각 $10 \mu \mathrm{M}$ 로 제조하여 1 시간 동안 노출시켰다. 화합물로 인한 췌장섬의 변 화를 관찰하기 위해 2차 현미경 촬영을 하였으며, 1 차 현미경 촬영과 동일하게 형광현미경 관찰 전에 $25 \mu \mathrm{M}$ 2-NBDG로 1시 간동안 다시 염색 하였다. 형광현미경을 통해 획득한 이미지는 Focus Lite 및 Image $\mathrm{J}$ 소프트웨어를 사용하여 zebrafish의 췌 장섬의 크기와 췌장섬의 형광 염색 intensity를 분석하였다. 실 험결과는 GraphPad Prism version 5.0 (GraphPad software, USA)를 이용하여 one-way ANOVA로 분석하였고, 집단 간 비 교를 위한 사후 분석은 Tukey로 검증하였으며, $p<0.05$ 이상일 때만 통계적 유의성이 있는 것으로 판단하였다. 실험결과는 3 반복 실시하여 평균표준편차로 나타내었다.

분리, 동정된 4종의 flavonoid의 췌장세포 회복효과를 검토하 기 위하여 zebrafish에 alloxan을 처리한 후 췌장섬의 손상을 유 발하였다. 항당뇨 화합물로 잘 알려진 glimepiride 및 4종의 flavonoid를 처리하여 손상된 췌장섬의 크기를 측정하여 회복 정 도를 확인하였다(Fig. 1). Alloxan은 췌장섬 내 $\beta$-cell만을 선택 적으로 파괴시키는 당뇨 유발물질로서 alloxan에 노출된 zebrafish는 alloxan을 처리하지 않은 zebrafish에 비해 41.2 $1.8 \%$ 췌장섬의 크기가 감소한 것을 확인하였다 $(p<0.001)$. 먼저 손상된 췌장섬을 항당뇨 물질로 이미 알려진 glimepiride에 노 출시켜 변화를 관찰하였다. Glimepiride는 감소된 췌장섬의 크 기를 무처리군 보다 $38.6 \pm 1.9 \%$ 증가시켰다. Astragalin, rutin, isoquercetin, quercetinc 처리 후 zebrafish의 췌장섬의 크기는 무처리군에 비해서 rutin 처리 그룹에서는 $32.3 \pm 1.7 \%$, isoquercetin 처리 그룹에서는 $63.9 \pm 20.3 \%$, quercetin 처리 그룹에서는 46.6 $\pm 15.4 \%$ 유의적 $(p<0.001)$ 으로 췌장섬의 크기를 증가시켰다. Rutin은 양성대조약물인 glimepiride보다 회복이 약하게 나타났 으나 isoquercetin은 양성대조약물에 비해 $25.3 \%$, quercetin은 $5.4 \%$ 더 회복된 것으로 나타났다. Astragalin은 무처리시의 췌 장섬의 크기만큼 회복되지는 않았지만, alloxan 처리로 손상 받 은 췌장섬을 상당히 회복시킨 것으로 나타났다.

Fluorescence intensity의 측정은 2-NBDG 염색 밝기를 측정 하는 것으로 세포 내 당 흡수 능력평가가 가능하며, 항당뇨를 평가하는 지표로 사용되고 있다(Yoshioka, 1996). Fluorescence 


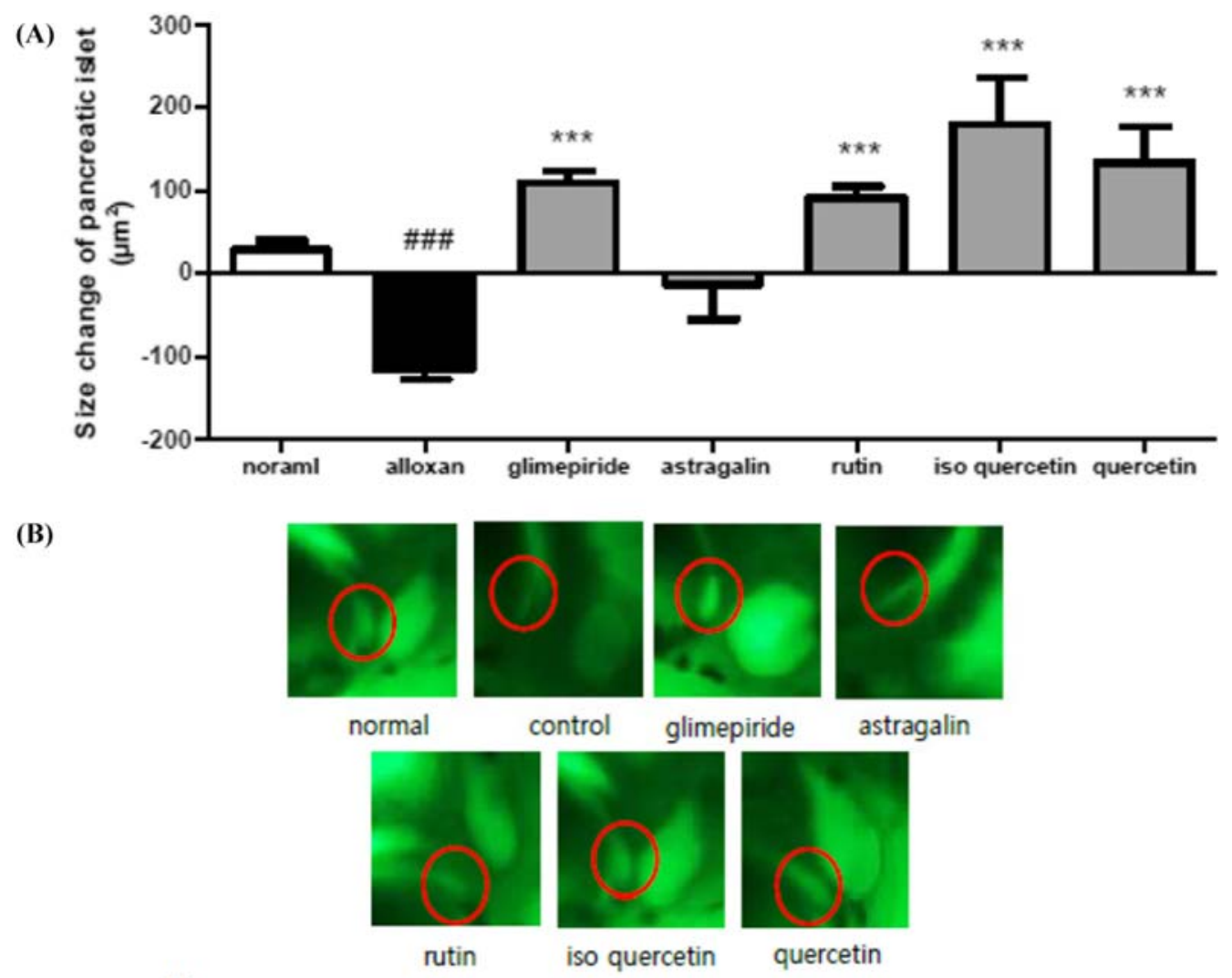

(C)

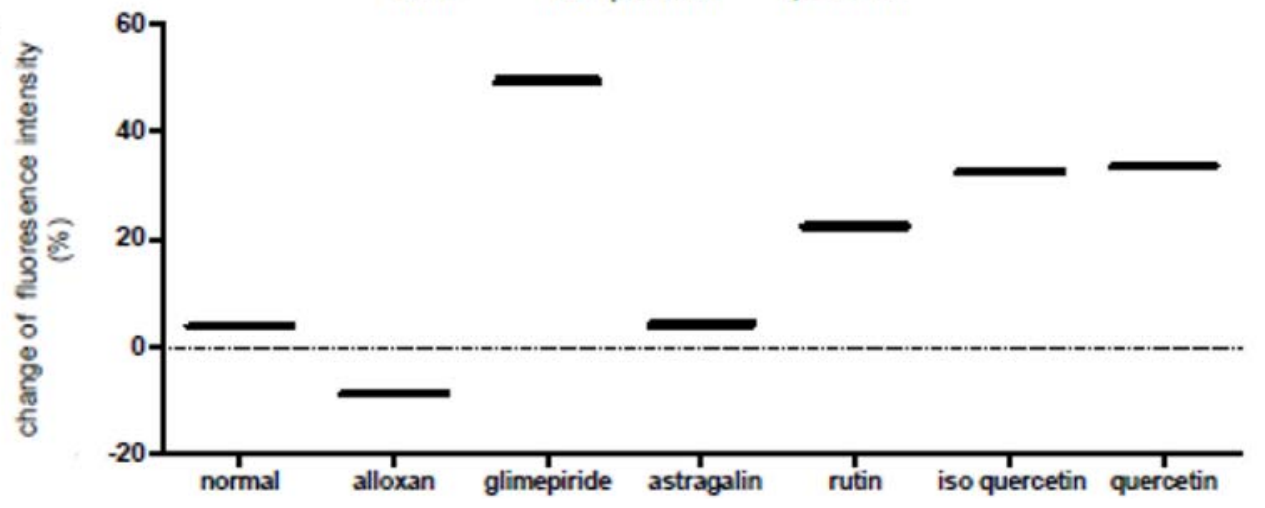

Fig. 2 Recovery effect of flavonoids from Morus alba fruits on alloxan-induced pancreatic islet in zebrafish. (A); Size change of pancreatic islet in zebrafish by treatment of alloxan, glimepiride, and flavonoids, astragalin, rutin, isoquercetin, and quercetin. (B); Pancreatic islet image of each group. (C); Change of fluorescence intensity of pancreatic islet evaluated by image analysis. $\left({ }^{*} p<0.05,{ }^{* *} p<0.01,{ }^{* * *} p<0.001\right.$; compared to alloxan), ${ }^{\sharp} p$ $<0.05,{ }^{\#} p<0.01,{ }^{\# \#} p<0.001$; compared to normal).

intensity 측정에서는 먼저 alloxan을 처리 후 양성대조 약물로 사용된 glimepiride의 경우, $49.4 \pm 3.8 \%$ 의 유의적인 증가를 확 인했다. Flavonoid의 경우 quercetin 처리 그룹에서 $33.5 \pm 2.7 \%$ 로 가장 높은 증가율을 보였고, isoquercetin 처리 그룹은 $32.6 \pm$ $2.2 \%$ 증가율을 나타냈다. Rutin 처리 그룹도 alloxan만 처리한 그룹보다 $22.4 \pm 1.8 \%$ fluorescence intensity가 증가하는 것으로 나타났다. Astragalin 처리 그룹은 $4.22 \pm 2.5 \%$ 증가하여 유의적 인 증가율을 나타내지 않았다. 종합하면, 분리한 4종의 flavonoid, rutin, isoquercetin, quercetin은 췌장섬의 크기와 fluorescence intensity에서 유의적인 증가율을 보여 항당뇨 효능 을 확인하였다 $(p<0.001)$ (Fig. 2). Flavonoid 화합물의 구조 활 성과의 관계를 보면, $\mathrm{B}$ 환의 $\mathrm{C}-3^{\prime}$ 위치에 수산기의 유무로 효능 차이가 나는 것을 알 수 있었으며, 육탄당이 2 분자 결합한 rutin 에 비해 육탄당이 1 분자 결합한 isoquercetin이 1.45 배 효능이 높게 나타났으며, 비 배당체인 quercetin은 1.49 배 높게 나타났 다. 따라서 결합한 당의 개수와 $\mathrm{B}$ 환의 C-3' 위치에 수산기의 유 무가 이번 실험의 효능에 매우 중요한 영향을 주는 것을 알 수 있었다. 


\section{초 록}

오디에서 분리한 flavonoid가 zebrafish에 alloxan을 처리하여 손 상된 췌장섬을 어느 정도 회복 시키는지 검토하였다. Zebrafish 의 배아에 alloxan을 처리하면 확실하게 췌장섬의 크기가 감소 하였다 $(p<0.001)$. Rutin, isoquercetin 및 quercetin의 처리에 의 해 췌장섬의 크기가 유의적으로 증가하였으며 $(p<0.001)$, 형광 세포의 fluorescence intensity도 뚜렷하게 증가하였다.

Keywords 뽕나무 · 오디 · 췌장섬 - 항당뇨 · alloxan · flavonoid · zebrafish

감사의 글 본 연구는 농림기술관리센터에서 지원하는 ‘오디로부터 색소 및 기능성 소재의 분리 동정 및 표준화’(과제번호:311025-03-3-SB010)로 수행 된 과제로 연구비 지원에 감사 드립니다.

\section{References}

Chae JW, Park HJ, Kang SA, Cha WS, Ahn DH, and Cho YJ (2012) Inhibitory effects of various mulberry fruits (Morus alba L.) on related enzymes to adult disease, J Life Sci 22, 920-7.

Gulubova R and Boiadzhiev TS (1974) Morphological changes in the dndocrine pancreas of the rabbit after the administration of a Morus alba extract, Eksp Med Morfol 14, 166-71.
Kim HT and Kim CH (2003) Zebrafish as a tool for functional genomics, Dev Reprod 7, 69-80.

Kim JS, Ju JB, Choi CW, and Kim SC (2006) Hypoglycemic and antihyperlipidemic effect of four Korean medicinal plants in alloxan induced diabetic rats, Am J Biochem Biotech 2, 154-60.

Kim SK (1991) Beneficial Medicine, Mulberry Fruit, In Bonchohak, pp. 598605, Yoinglimsa, Korea

Kim TW, Kwon YB, Lee JH, Yang IS, Youm JK, and Lee HS (1996) A study on the antidiabetic effect of mulberry fruits, Korean J Seric Sci 38, 1007.

Lee JW, Seo BI, Park JH, Roh SS, Kim YH, and Kim MR (2009) Effect of Mantidis OÖtheca and Mori fructus on treatment of osteoporosis in ovariectomized rats. Kor J Herbology 24, 59-71.

Lenzen S (2008) Beta-cell apoptosis in type 2 diabetes: Quantitative and functional consequences. Diabetes Metab 34, 56-64.

Park SJ and Jeong JC (2008) ROS-, RNS-Scavenging and anti-inflammatory activities of Mori Fructus. J Korean Oriental Med 29, 106-16.

Park SW, Chung IS, and Ko GC (1997) Quantitative Analysis of Anthocyanins among Mulberry Cultivars and Their Pharmacological Screening. J Korean Soc Food Sci Nutr 38, 722-4.

Seo HH and Jeong JM (2014) Inhibitory effects of complex of mulberry extract on degenerative arthritis. Korean J Medicinal Crop Sci 22, 262-9.

Yoshioka K, Saito M, Oh KB, Nemoto Y, Matsuoka H, and Natsume M (1996) Intracellular fate of 2-NBDG, a fluorescent probe for glucose uptake activity, in Escherichia coli cells, Biosci Biotech Bioch 60, 1899 901.

Zou C, Wang Y, and Shen Z (2005) 2-NBDG as a fluorescent indicator for direct glucose uptake measurement. $J$ Biochem Biophys Methods 64, 207-15. 